\title{
Deformation Mechanism and Surrounding Rock Control in High-Stress Soft Rock Roadway: A Case Study
}

\author{
Yuwen Gao, ${ }^{1}$ Chen Wang $\left(\mathbb{D}^{1},{ }^{1}\right.$ Yong Liu, ${ }^{1}$ Yuyang Wang, ${ }^{1}$ and Lianchang Han ${ }^{2}$ \\ ${ }^{1}$ School of Mining, Guizhou University, Guiyang 550025, China \\ ${ }^{2}$ Guizhou Panjiang Refined Coal Co., Ltd., Panzhou 553529, China
}

Correspondence should be addressed to Chen Wang; cwang@gzu.edu.cn

Received 4 April 2021; Accepted 29 May 2021; Published 25 August 2021

Academic Editor: Zizheng Zhang

Copyright (c) 2021 Yuwen Gao et al. This is an open access article distributed under the Creative Commons Attribution License, which permits unrestricted use, distribution, and reproduction in any medium, provided the original work is properly cited.

Stability control for soft and broken surrounding rock of roadways is one important segment of mining support. Taking 1412 Roadway of a mine in Guizhou province as a research background, this paper studies the large deformation of surrounding rock and the failure of bolts and cables. The deformation and failure mechanism are analyzed by related theoretical analysis and field survey. Then, the feasibility of the composite controlling scheme, bolts and cables + grouting + steel tube concrete support, is verified by theoretical analysis, numerical simulation, and industrial test. Following results can be obtained: main reasons leading to the deformation of surrounding rock and the failure of cables and blots in the roadway are low strength and poor self-stability of surrounding rock, complex stress environment, low support resistance, and lack of reinforced support in crucial supporting sites; the control scheme can reduce the surrounding rock deformation by $40 \%$, which meets the requirements of field application so that this practice can provide some guidance for other similar projects.

\section{Introduction}

Deformation and failure control of surrounding rock in soft rock roadway are always regarded as a difficult problem within worldwide underground engineering. With the depletion of coal resources in shallow bed, the mining depth increases incrementally and the number of soft rock roadway with high stress as well. Besides, unfavorable conditions such as high in situ stress and strong disturbance, soft and broken surrounding rock increase the difficulty of surrounding rock deformation and failure control [1-3].

For roadways with the loose and broken surrounding rock, traditional control techniques including anchor note, bolting shotcrete, cable anchor, u-steel yieldable support, concrete, and reinforced concrete hardly work to maintain the roadway stability especially under the influence of high stress and strong disturbance [4-6]. Compared with traditional support materials, the concrete-filled steel tube support is better than them in mechanical properties. Take an example, the support has three times bearing capacity of U-steel support under the same volume of steel. In recent years, concrete-filled steel tube support has been applied on the field to control the deformation in soft rock roadway $[7,8]$. Li et al. [9] proposed and applied "high-strength concrete-filled steel tube" supporting scheme to control the surrounding rock deformation in Chaganmuer mine so that the deformation and destruction had been effectively controlled; Liu et al. [10] used the closed-end composite supporting scheme "anchor net spray + oval concrete-filled steel tube supports + steel fiber concrete + reinforcement cable" to address the problem of deformation control in Qingshuiying coal mine large-section soft rock roadway; Wang et al. [11] applied "elliptical concrete-filled steel tube supports + deepshallow cross grouting reinforcement" composite supporting scheme to reduce surrounding rock deformation in the Xingdong mine, and the scheme has worked effectively; Gao et al. [12] proposed and applied high-strength composite support technology based on concrete-filled steel tube support to successfully control surrounding rock deformation and failure.

In short, the advantages of concrete-filled steel tube support have been confirmed in several soft rock roadways 
in China [13-15]. Nevertheless, this technology has not been utilized to soft and broken swelling rock roadways influenced by high stress and strong disturbance.

According to the on-site survey, 1412 Roadway belongs to a soft and broken swelling rock roadway influenced by high stress and strong disturbance. And, deformation and destruction of the surrounding rock were serious, which restricts normal production. Based on the analysis of the surrounding rock deformation characteristics and mechanism, the composite supporting scheme, bolts and cables + grouting + steel tube concrete support, has been put forward and verified by the industrial test. In brief, this scheme can provide a reference for the surrounding rock control under similar conditions.

\section{Engineering Background}

With depth of embedment between $650 \mathrm{~m}$ and $850 \mathrm{~m}, 1412$ Roadway is located at an intersection of many roadways in $17 \#$ coal seam. Coal seam group consisting of $16 \#, 17 \#$, and $18 \#$ coal seam is a close-distance coal seam group. Besides, the adjacent coal seams of $17 \#$ coal seam have been hollowed out one after the other. In addition, the superposition of disturbed stress field and primary stress field formed by multiple disturbances makes the roadway stress environment complicated. And, the surrounding rock lithology is dominated by mostly weak rock such as mudstone, shale, fine sandstone, and silty mudstone. When such rocks are exposed with water, it easily generates great swelling pressure. Furthermore, the phenomenon of stress concentration appears serious. The local vertical stress exceeds $20 \mathrm{MPa}$, which belongs to the high-stress soft rock roadway.

For the original supporting scheme, "anchor net + cable + bolt-shotcrete" had been adopted. The bolt adopts left spiral rigid bolt with diameter $22 \mathrm{~mm}$ and length $2000 \mathrm{~mm}$. The distance between adjacent rows of the bolt is $800 \mathrm{~mm}$. The specification parameters of the initial cable, respectively, are diameter $22 \mathrm{~mm}$ and length $6000 \mathrm{~mm}$. The distance between adjacent rows of the cables is $1200 \mathrm{~mm}$. The hanging net is diamond-shaped metal net, and the thicknesses of the sprayed concrete are $150 \mathrm{~mm}$. The dimension of original roadway section, respectively, is net width $5500 \mathrm{~mm}$, wall height $860 \mathrm{~mm}$, arch height $2750 \mathrm{~mm}$, and clear height $3610 \mathrm{~mm}$.

\section{Analysis of Deformation Characteristics and Mechanism}

3.1. Deformation and Failure Characteristics of Surrounding Rock. Through the field investigation and records about 1412 Roadway, these deformation characteristics can be obtained:

(1) The surrounding rock has great deformation and rapid deformation rate. The initial convergence speed is up to $60 \mathrm{~mm} /$ day after roadway excavation. And, the maximum deformation amount among the roof, the floor heave, and the two sides, respectively, come to $1155 \mathrm{~mm}, 580 \mathrm{~mm}$, and between $1500 \mathrm{~mm}$ and $2200 \mathrm{~mm}$.
(2) Clay mineral will be expanded, and mudding occurs when it exposes to water, which aggravates rock deformation. The studied roadway surrounding rock contains a large number of clay minerals including montmorillonite and illite. Therefore, the surrounding rock sharply causes softening and mudding phenomenon with water.

(3) The supporting components are seriously ineffective. In key parts such as the roof, the shoulder socket, and the two sides of roadway, the failure of bolts and cables frequently happened. The failure features mainly perform breakage, slippage, exfoliated nut, pallet bending, and fracturing. And, the metal mesh pockets appeared to have tear and local rock fall.

(4) The surrounding rock expresses loose and broken in a wide range. Using YTJ-20 rock formation drilling detector to drill the surrounding rock at field, the detection result presents the range of loose circle which is between $2.3 \mathrm{~m}$ and $4.2 \mathrm{~m}$, which is beyond anchorage range of the bolts. Hence, the bolts are difficult to play an active support role. Figure 1 shows part deformation characteristics of the roadway.

\subsection{Mineral Composition Analysis and Mechanical Properties'} Test. Using the PANalytical multifunctional powder X-ray diffractometer in room for the composition analysis of the surrounding rock, the mineral compositions are shown in Table 1.

Using the HDH-1 point load test instrument to conduct a point load test in this roadway, the average uniaxial compressive strength of the floor rock and roof rock, 1.23 MPa, can be obtained. The above results present that the strength of the surrounding rock is extremely low.

\subsection{Deformation and Failure Mechanism of Surrounding Rock}

(1) The surrounding rock has such characteristics of low strength and poor self-stability. The major lithology of the surrounding rock is dominated by soft rocks such as mudstone, shale, fine sandstone, and silty mudstone. Mudstone, fine sandstone, and other mineral mainly consist of quartz. Besides, there is a higher content of clay minerals, including plagioclase and albite, in the surrounding rock. These clay minerals are easy to expand when exposed to water, which produces huge swelling pressure and aggravates roadway deformation. Furthermore, the fracture and joints of the surrounding rock developed, resulting in surrounding rock loose and broken with low bearing capacity.

(2) The roadway was significantly affected by repeated mining. And, the stress environment is complex. The mining effect mainly comes from the mining of the close coal seam group. Besides, the roadway is located near the intersection of various roadways. The superposition of the disturbed stress field, formed by multiple disturbances, and the primary stress field 


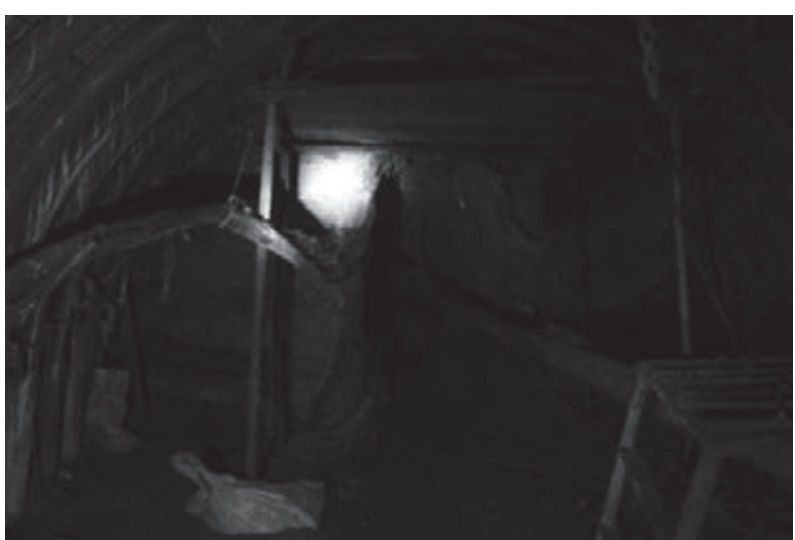

(a)

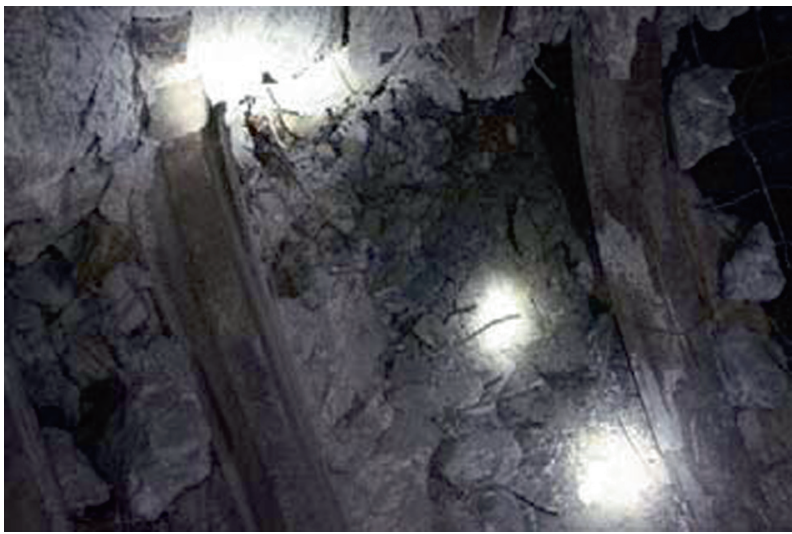

(c)

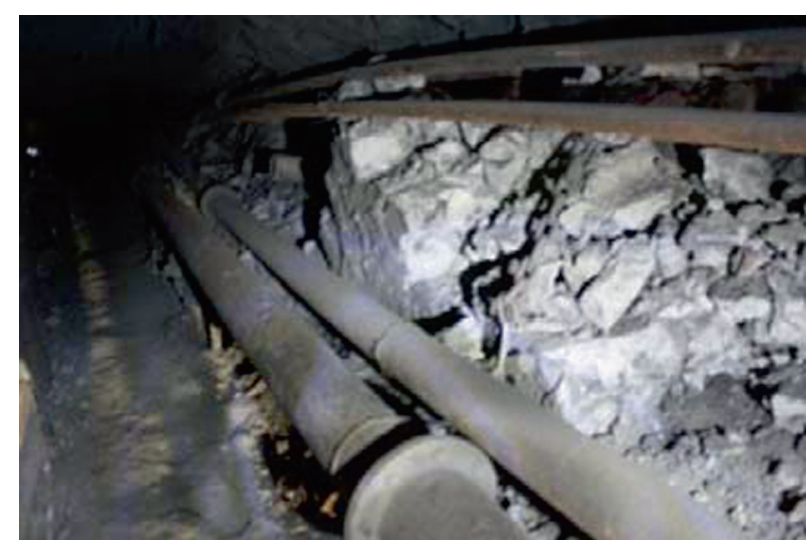

(b)

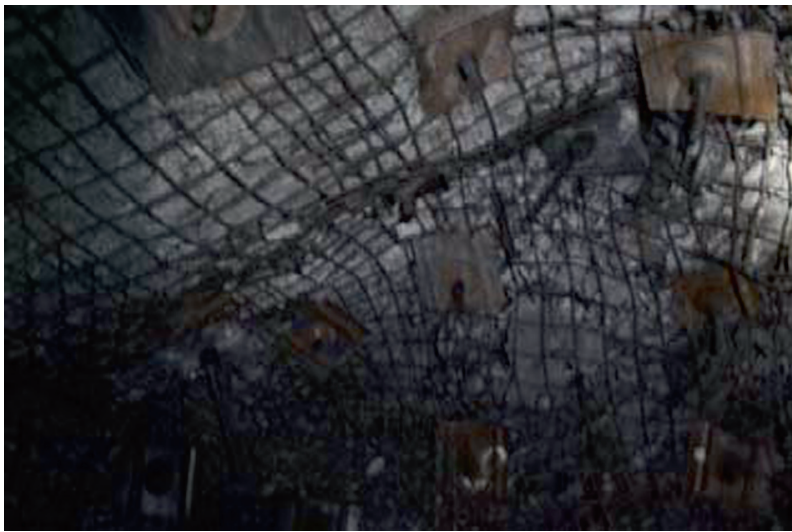

(d)

FIGURE 1: Roadway deformation figure under original support. (a) Section deformation. (b) Large deformation of section. (c) Broken surrounding rock. (d) Pallet bending.

TABle 1: Mineral composition and content.

\begin{tabular}{lc}
\hline Mineral composition & Content (\%) \\
\hline Clay mineral & 70.4 \\
Quartz & 18.1 \\
Plagioclase & 8.4 \\
Albite & 3.1 \\
Montmorillonite & 33 \\
Kaolinite & 42 \\
Illite & 12 \\
Chlorite & 13
\end{tabular}

contributes to the more complicated stress environment. Furthermore, the phenomenon of stress concentration has intensified.

(3) The primal supporting parameters are unreasonable. The length of the original support bolt is $2.0 \mathrm{~m}$, and the distance between adjacent rows is $800 \mathrm{~mm}$. The length of the anchor cable is $6 \mathrm{~m}$, and the distance between adjacent rows is $1200 \mathrm{~mm}$. Owing to the range of loose circles exceeded the length of original bolts, the active bearing capacity of the bolts and the cables was not fully utilized. With unreinforced support, vital parts such as bottom corners, shoulder, and roof have serious damage.

(4) The mudding phenomenon of surrounding rock is serious. The roof and the two sides had serious seepage. Long-term contact between surrounding rock and water causes the strength and the bearing capacity of the surrounding rock decrease. Secondly, water leads to expansion and sliming of the surrounding rock which contains a large number of montmorillonite and kaolinite. Thereby, the selfsupporting capacity of the surrounding rock becomes low.

(5) There was unreinforced support on the floor and the bottom corner. After excavation, the floor was opening and unsupported, which belongs to the weakest link of support. In addition, the effect of water dripping from roof and water accumulation on floor contributed to that the floor undergoes significant swelling deformation and rheological deformation. The floor has seriously deformed and the roof and two sides as well. Eventually, the supporting structure became unstable and damaged. 


\section{Deformation and Failure Control Technology of Surrounding Rock}

4.1. Control Principles of Roadway Surrounding Rock Deformation. In order to effectively control the deformation and destruction of 1412 Roadway and to choose the optimal supporting scheme, following supporting principles should be complied:

Governing sequence: Govern floor $\longrightarrow$ Govern two sides $\longrightarrow$ Govern roof. Furthermore, the shoulder corner is also a vital position which should be supported.

Active supporting improves integrity of the surrounding rock; thus, let surrounding rock give full play to the active bearing performance. There are some aspects that should be specifically considered:

(1) Strengthen support for critical parts: instability and deformation of the roadway start from crucial positions which determines the stability of the overall structure. When there are weak links in the surrounding rock, it is frequently the breakthrough point of deformation and destruction. And, the malignant expansion of weak links will eventually lead to instability and deformation over time. Therefore, these critical parts should be reinforced to avoid stress concentration, so as to improve the overall performance of the surrounding rock and control the instability and the deformation.

(2) Strengthen support on the floor: the type of floor heave is squeezing fluidity floor heave in 1412 Roadway. Shearing damage occurs in the unsupported floor strata under the action of high stress, which causes cracks and gaps in the floor. Otherwise, the invasion of water will aggravate the destruction. Therefore, bolts will be used to cut off pressure transmission of the two sides. Furthermore, the hardening grouting concrete can provide a large amount of bearing capacity. And, the stress state of the floor is transformed from the two-direction stress state to three-direction stress state. In other words, the ultimate strength of the floor rock is improved. The bearing range of stress is gradually enlarged. And, the floor heave can be effectively controlled.

(3) Use strong bolts and high prestressed cables: at the initial stage of roadway support, the cables and the bolts undertake main carrying work. By increasing the initial pretightening force of supporting components, it can form an effective prestressed loadbearing structure and that exerts the characteristics of bolts and cables rapidly increase resistance, strong initial support, and high working resistance. In addition, it can likewise restrain discontinuous deformation and expansion of surrounding rock within anchorage scope such as separation, sliding, and crack propagation. In other words, the measure ensures the integrity of surrounding rock and improves the rock's active bearing capacity.
(4) Implement full-section grouting behind wall and strengthen the carrying capacity of surrounding rock: full-section grouting not only can seal or even fill the water flowing fracture in the surrounding rock but also prevent the erosion of water and strengthen the strength of surrounding rock. Secondly, grouting can penetrate into fractures of broken surrounding rock under the action of highpressure pump. Besides, grouting can fill or even close larger fractures. The consolidated permeable slurry can form a network skeleton structure, so as to improve the strength of surrounding rock. The cables and bolts are arranged inside the grouting layer, which is conducive to prestressed diffusion and improving the stress state. The stress state of surrounding rock transforms from two-direction stress to three-direction stress. After the roadway is widened to the designed section, the bolts and cables, concrete-filled steel tube support, and concrete coordinate with the surrounding rock to form a collaborative supporting system, which achieves a hierarchical coordinated load-bearing layer.

In other words, the first bearing layer is made of concrete-filled steel tube support and hardened concrete. The combination of these supports cannot only resist high strength pressure but also moderate pressure relief. For the stress environment where pressure around the roadway is large and uneven, the layer can provide great bearing capacity.

The arching effect of high-strength bolts improves the stress state of shallow surrounding rock, transforms anchoring area from the load body into the bearing body, and restricts the destruction and deformation of shallow surrounding rock. The influenced layer is named the second bearing layer.

The high prestressed anchor cable anchored in the stable rock layer effectively links shallow broken surrounding rock and deep stable surrounding rock. Therefore, this and the arching action of anchor bolts together form the third bearing layer, which controls the deformation of surrounding rock.

4.2. Deformation Control Strategy and Parameter Determination of Surrounding Rock. Derived from the above analysis, the support theory of high stress soft rock roadway, and field experience, a preliminary design of composite supporting scheme "anchor cables and bolts + grouting + concrete-filled steel tube support' is designed, as follows:

(1) The original roadway adopts straight wall semicircular arch roadway, which cannot provide any support for the floor. The deformation first occurs from weak link in the support, that is, the place where stress is concentrated. Using horseshoe-shaped roadway section as roadway section not only avoids weak links but also improves stress state of the surrounding rock. 
(2) The prestress of the original bolt and the support strength of the initial proposal are lower. It has been tested that the surrounding rock within $1.7 \mathrm{~m}$ was severely broken. In order to give full play to the restriction of the bolts on the shallow surrounding rock's deformation and destruction, the length of bolts is extended to $2500 \mathrm{~mm}$. The anchor bolt adopts ultraintense thread steel bolt with diameter $22 \mathrm{~mm}$. The distance between adjacent rows of bolt is $800 \mathrm{~mm}$. There are 15 bolts arranged in each row of the roadway, and each bolt uses 3 rolls of K2335 resin medicine (fixative). In addition, since the floor heave type is a squeezing fluidity floor heave, the inclination angle of the bolt which is arranged at corner should be set between $20^{\circ}$ and $30^{\circ}$ to cut off the stress transmission between the two sides. The bolt screws must be tightened by plum blossoms with diameter $34 \mathrm{~mm}$. Tightening torque is between $150 \mathrm{~N} \cdot \mathrm{m}$ and $200 \mathrm{~N} \cdot \mathrm{m}$. The anchor bolt is lapped at the overlap of steel mesh. The length and width of the steel mesh are, respectively, $1800 \mathrm{~mm}$ and $980 \mathrm{~mm}$. The anchoring section length takes $1500 \mathrm{~mm}$. And, the overlap length of the steel mesh fetches $100 \mathrm{~mm}$. The cables adopt prestressed cable with diameter $21.6 \mathrm{~mm}$ and length $7000 \mathrm{~mm}$. The distance between adjacent rows of the cables has $1200 \mathrm{~mm}$. And, each row is arranged with 7 anchor cables. Moreover, each anchor cable uses 5 anchoring agents. The pretightening force of the cable is not less than $150 \mathrm{~N} \cdot \mathrm{m}$. The exposed length of the cable is between $150 \mathrm{~mm}$ and $250 \mathrm{~mm}$ after tightening.

(3) For maintaining the stability of the roadway with high stress and intense surrounding pressure, the surrounding rock not only needs bearing capacity from itself but also needs external supporting force. In this paper, concrete-filled steel tube support is selected as a crucial part of the active support. The concrete-filled steel tube support has same shape as the roadway section and uses $20 \#$ seamless steel pipes with diameter $194 \mathrm{~mm}$ and wall thickness $10 \mathrm{~mm}$. The specification of casing selects diameter $219 \mathrm{~mm}$ and length $100 \mathrm{~mm}$. And, a set of concrete-filled steel tube support is erected every $500 \mathrm{~mm}$. Using HBTS15 concrete pump, C40 concrete was injected into inner of the support from bottom to top. The mixing ratio of cement, water, and sand fetches $1: 0.39: 1.29$ in C40 concrete. The pressure value of the transfer pump gets to about $5 \mathrm{MPa}$, which can be adjusted according to the actual situation, but the maximum pressure cannot exceed $6 \mathrm{MPa}$. Due to the deep loose and broken range of surrounding rock, the arching effect of bolt hardly works. Therefore, a $500 \mathrm{~mm}$ gap between roadway and support for high-pressure grout was left when erecting the concrete-filled steel tube supports. The slurry under the action of high pressure penetrates in the deep surrounding rock to improve the integrity. The grouting pressure value takes $6 \mathrm{MPa}$, and the wind pressure is controlled at
$0.15 \mathrm{MPa}$ to $0.18 \mathrm{MPa}$. After the bolts and cables are laid, the bottom grout is conducted, and then, the support has erected. Secondly, reinforced mesh and noncombustible material cloth are laid behind the support. The mixing ratio of cement and sand takes $1: 3$ in cement mortar. And, the mixture must be mixed evenly with accelerator which accounts $3 \%$ to $5 \%$ of the cement amount. Besides, the storage time of the mixture with accelerator cannot get past twenty minutes. The composite supporting scheme is shown in Figure 2.

\section{Check Bearing Capacity of the Composite Support Scheme}

5.1. Calculate Support Resistance of the Concrete-Filled Steel Tube Support. The support resistance of the concrete-filled steel tube support can be calculated through the following formula:

$$
\begin{gathered}
\sigma_{0}=\frac{\varphi_{0} N_{0}}{D R_{S}}, \\
R_{S}=k_{m} \sqrt{\frac{S_{S}}{\pi}},
\end{gathered}
$$

where $S_{S}$ presents the area enclosed by the concrete-filled steel tube support, $\mathrm{m}^{2}, \varphi_{0}$ represents the reduction factor, taking 0.80 , and $N_{0}$ represents the ultimate bearing capacity of the concrete-filled steel tube short columns. Due to the steel tube adopted diameter $194 \mathrm{~mm}$ and thickness $10 \mathrm{~mm}$, $N_{0}$ takes $3186.4 \mathrm{KN}$; $D$ represents the spacing of the support, taking $0.5 \mathrm{~m} ; k_{m}$ is the section correction factor, taking 1.05 [16]. The section area is $14.84 \mathrm{~m}^{2}$. Bring each parameter into formula (3), it can be obtained that $\sigma_{0}$ is $2.24 \mathrm{MPa}$.

5.2. Calculate Support Resistance of Grouting Body. The support resistance of hardened concrete can be calculated through the following formula [17]:

$$
\begin{aligned}
& P_{c}=\frac{2 \tau_{c} d_{c}}{R_{c} \sin 2 \gamma}, \\
& R_{c}=k_{m} \sqrt{\frac{S_{c}}{\pi}},
\end{aligned}
$$

where $\tau_{c}$ represents shear strength of grout, $\tau_{c}=0.15 f_{c}, f_{c}$ represents the designed compressive strength of grout, taking $12 \mathrm{MPa}, d_{c}$ represents thickness of the grouting body, taking $500 \mathrm{~mm}, \gamma$ represents the shearing slip angle, taking $33^{\circ}$, and $S_{c}$, area enclosed by the grouting body, is $18.07 \mathrm{~m}^{2}$. Bringing each parameter into formula (2), it can be obtained that $P_{c}$ is $0.782 \mathrm{MPa}$.

5.3. Calculate Support Resistance of Bolt and Cable. Computed mechanical model of the superimposed bearing layer is shown Figure 3.

Calculate the effective length of the bolt and cable [18]: 


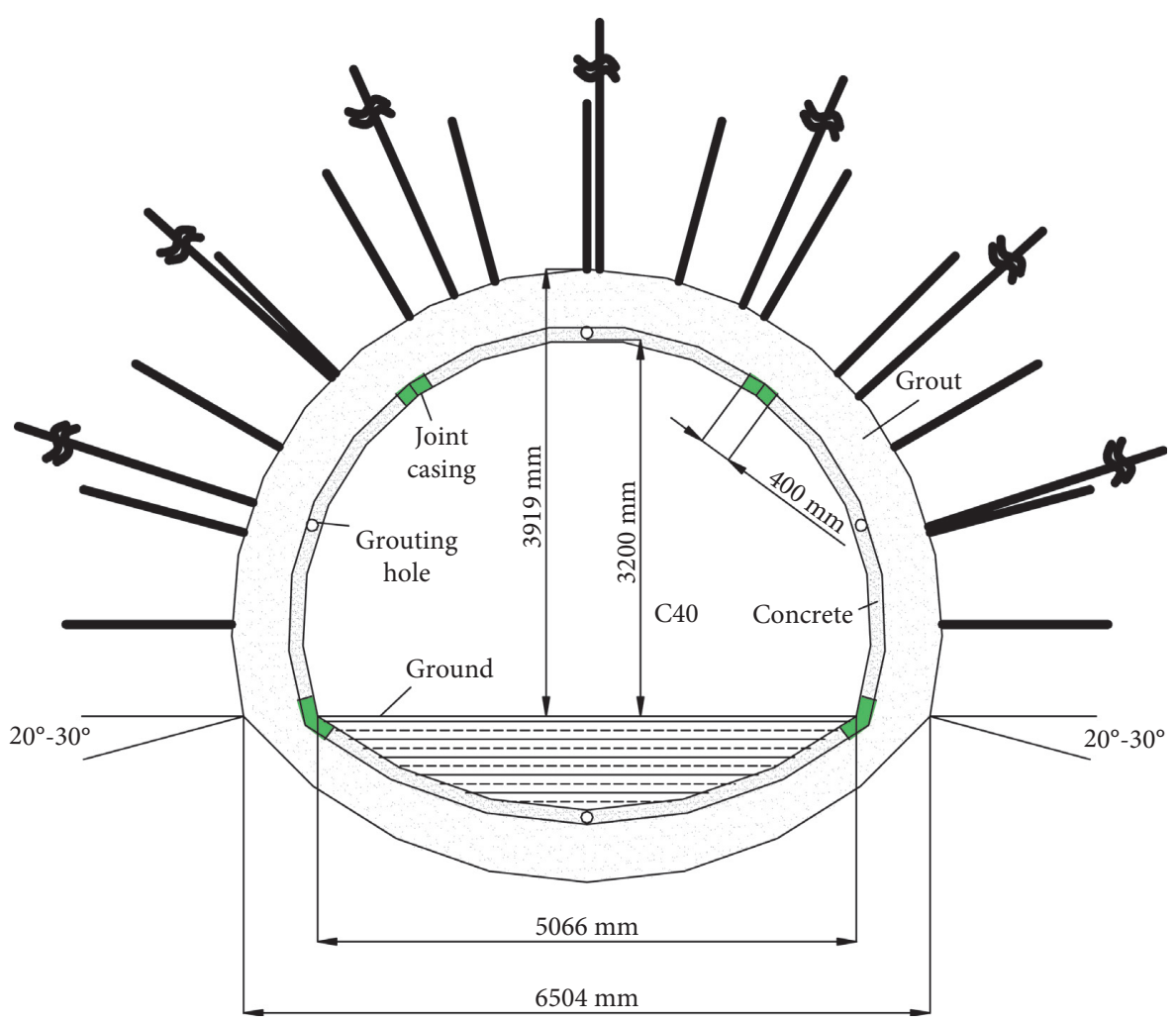

Figure 2: Composite support schematic.

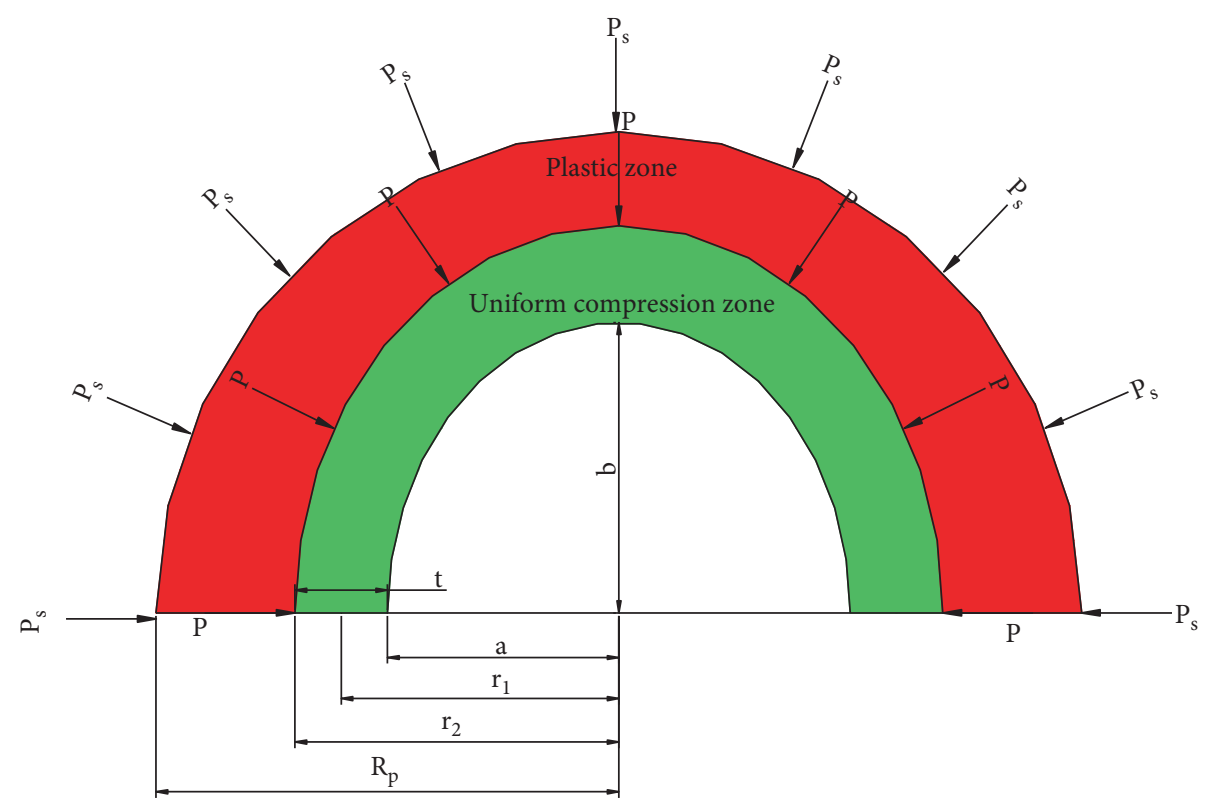

Figure 3: Mechanical model of the arched compression zone.

$$
\begin{aligned}
& t_{1}=\frac{L_{1} \tan \beta-D_{1}}{\tan \beta}, \\
& t_{2}=\frac{L_{2} \tan \beta-D_{2}}{\tan \beta},
\end{aligned}
$$

where $L_{1}$ is the effective length of bolt, $L_{1}=L_{1}^{\prime}-L_{a}-L_{b}$, $L_{1}^{\prime}$ is a length of the bolt, taking $2.5 \mathrm{~m}, L_{a}$ is an exposed length of the bolt, taking $0.15 \mathrm{~m}, L_{b}$ is an end length of the bolts, taking $0.5 \mathrm{~m}, \beta$ is the control angle of the cable and the bolt in the ruptured surrounding rock, taking $45^{\circ}, L_{2}$ is the effective length of the cable, $L_{2}=L_{2}^{\prime \prime}-L_{c}-L_{d}, L_{2}^{\prime \prime}$ is a length of the 
cable, taking $7 \mathrm{~m}, L_{c}$ is an exposed length of the cable, taking $0.2 \mathrm{~m}, L_{d}$ is an end length of the cable, taking $2.5 \mathrm{~m}, h_{c}$ is thickness of the grouting body, taking $0.5 \mathrm{~m}$, and $D_{1}$ and $D_{2}$, respectively, presents the distance between adjacent rows of the bolt and cable, taking $0.8 \mathrm{~m}$ and $1.2 \mathrm{~m}$. Bringing each parameter into formula (5), it can be obtained that $t_{1}$ and $t_{2}$ are, respectively, $1.05 \mathrm{~m}$ and $3.10 \mathrm{~m}$. The model of the bearing layer structure is shown as Figure 4.

The radial axial force provided by the cable and bolt can be calculated by the following formula:

$$
\begin{gathered}
\sigma_{S}=\frac{F_{S}}{D_{2} * D_{2}}, \\
\sigma_{g}=\frac{F_{g}}{D_{1} * D_{1}},
\end{gathered}
$$

where $F_{s}$ is the pulling force of the cable and $F_{g}$ is the pulling force of the bolt. According to the specification of the selected bolt and cable, it can be obtained that $F_{s}$ and $F_{g}$ are, respectively, $454 \mathrm{kN}$ and $127 \mathrm{kN}$. By calculating, $\sigma_{s}$ and $\sigma_{g}$ are, respectively, $0.31 \mathrm{MPa}$ and $0.20 \mathrm{MPa}$.

The relationship between tensile force of a bolt and weight of the rock mass it bears is as follows:

$$
F_{g}>\rho * D_{1}^{2} * g * L_{1}^{\prime} * 1.8=41.6 \mathrm{KN},
$$

where $\rho$ is the density of strata passed by the bolt, taking $2600 \mathrm{~kg} \cdot \mathrm{m}^{-3}, g$ presents acceleration of gravity, taking $10 \mathrm{~N} /$ $\mathrm{kg}$, and 1.8 represents the safety factor.

It can be seen from the above equation that the tensile force is greater than the rock mass gravity, so the bolt spacing is reasonable.

\subsection{Check Bearing Capacity of Uniform Compression Zone.} This paper focuses on the elliptic section in the upper half of the roadway, so the hyperbolic section in the lower part will not be discussed. On the horseshoe roadway section, the stress state of the upper half of the surrounding rock can be equivalent to the stress state of the upper surrounding rock of the elliptical roadway under the same load.

In this paper, the ratio of long axis to short axis is 1.26 , which is high elliptical roadway. The plastic area boundary of high elliptical roadway is close to circular, so the boundary of the plastic area in the upper half of the roadway in this paper is equivalent to semicircle [19].

Based on the principle of the arched compression zone, the mechanical model of elliptical roadway under stress in original rock is established, as shown in Figure 3.

The boundary outside the plastic zone, that is, the boundary inside the elastic zone, meets the following equation [20]:

$$
\begin{aligned}
\sigma_{\theta(p)}+\sigma_{\rho(p)} & =2 P_{0}, \\
\sigma_{\theta(p)} & =\frac{1+\sin \varphi}{1-\sin \varphi} \sigma_{\rho(p)}+\frac{2 c \cos \varphi}{1-\sin \varphi} .
\end{aligned}
$$

The following equation can be obtained from the above equations:

$$
\sigma_{\rho(p)}=(1-\sin \varphi) P_{0}-c \cos \varphi
$$

where $P_{0}$ represents the initial ground stress, $\varphi$ represents the internal friction angle, $c$ represents cohesion, and $R_{p}$ is the radius of the surrounding rock plastic area. According to the experimental results and field measurement, $\varphi$ takes $27^{\circ}$, $c$ is $0.37 \mathrm{MPa}, R_{p}$ is $6700 \mathrm{~mm}$, and $P_{0}$ is $17.24 \mathrm{MPa}$. Bringing each parameter into the formula, it can be obtained that $\sigma_{\rho(p)}$ is $9.08 \mathrm{MPa}$.

The load $P$ acting on the uniform compression zone formed by bolts and cables can be obtained by using the Jager and Cook formulas $[20,21]$

$$
P=P_{s}\left(\frac{r_{2}}{R_{p}}\right)^{2 \sin \varphi /(1-\sin \varphi)} .
$$

The elliptic equation can be expressed in the form of polar coordinates, as shown in the following:

$$
\begin{aligned}
\rho & =\frac{a b}{\sqrt{b^{2} \cos ^{2} \theta+a^{2} \sin ^{2} \theta}}, \\
r_{2} & =\frac{a b}{\sqrt{b^{2} \cos ^{2} \theta+a^{2} \sin ^{2} \theta}}+t, \\
P_{s} & =\sigma_{\rho(p)},
\end{aligned}
$$

where $\theta$ is the angle between the stress and the horizontal axis. Since the number of cables used in this roadway is fewer, the effective length of the bolt is taken as the width of the uniform compaction zone:

$$
t=t_{1} \text {. }
$$

Bringing formulas (7) and (10) into formula (8), the following equation can be obtained:

$$
P=P_{s}\left(\frac{a b+t_{1} \sqrt{b^{2} \cos ^{2} \theta+a^{2} \sin ^{2} \theta}}{R_{p} \sqrt{b^{2} \cos ^{2} \theta+a^{2} \sin ^{2} \theta}}\right)^{2 \sin \varphi /(1-\sin \varphi)} .
$$

The schematic diagram of the force on the arch formed by the uniform compression zone is shown in Figure 5.

Under the action of only considering the supporting force, the radial stress in the uniform compression zone upper part can be calculated by the following complex variable function method to shortcut calculation.

Through the mapping function, the shadow part in the $Z$ plane will be mapped to the shadow part in the corresponding complex plane [22]. Curve $L$ and points $A, B, C$, and $D$ in the $z$ plane are mapped to complex plane curve $L^{\prime}$ and points $A^{\prime}, B^{\prime}$, $C^{\prime}$, and $D^{\prime}$, respectively. The mapping relationship and schematic diagram are shown in Figure 6.

$$
\begin{aligned}
& z=w(\zeta)=R\left(m \zeta+\frac{1}{\zeta}\right) \\
& R=\frac{a+b}{2} \\
& m=\frac{a-b}{a+b}
\end{aligned}
$$






Figure 4: Model of the bearing layer structure.

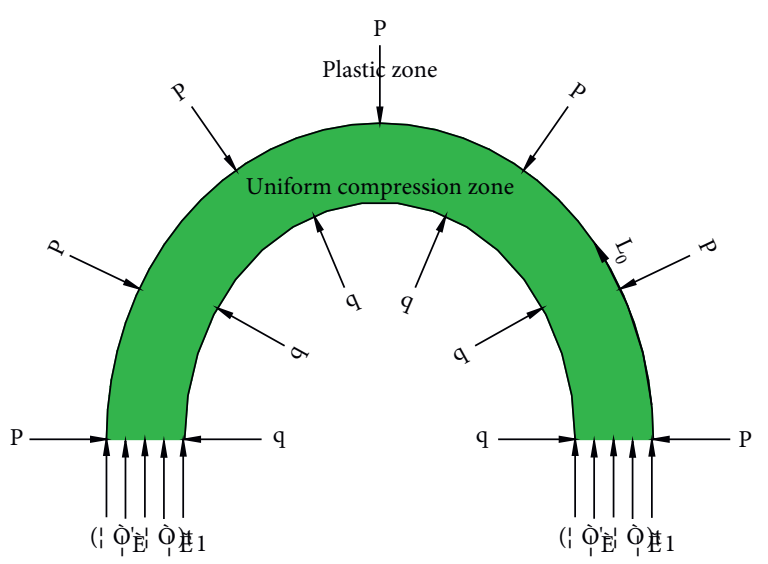

Figure 5: Force diagram of the arch.

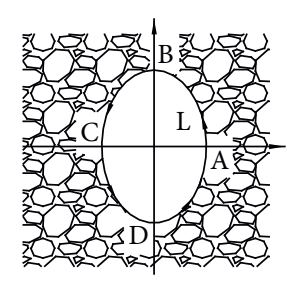

Z-plane

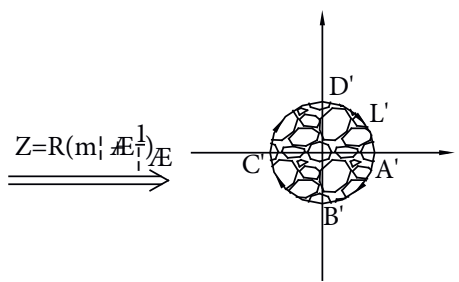

; Æplane
Figure 6: Mapping diagram. where $\mathrm{a}$ and $\mathrm{b}$ are the semilong axis and semishort axis of an ellipse, respectively.

Assuming that the roadway after support following the basic hypothesis of elasticity, the stress function can be expressed as follows:

$$
U=\frac{1}{2}[\bar{z} \chi(z)+z \overline{\chi(z)}+\theta(z)+\overline{\theta(z)}]
$$

where $z$ represents point coordinates in the complex plane and both $\chi(z)$ and $\theta(z)$ are analytic functions.

When considering only the effect of support force on roadway surrounding rocks, the following equation is met on the roadway boundary:

$$
\begin{aligned}
f_{0}= & i \int_{L}\left(\overline{T_{x}}+i \overline{T_{y}}\right) \mathrm{d} s-\frac{X+i Y}{2 \pi} \ln \sigma-\frac{1+\nu^{\prime}}{8 \pi} \\
& \cdot(X-i Y) \frac{w(\sigma)}{\overline{w(\sigma)}} \sigma-2 B w(\sigma)-\left(B \prime-i C^{\prime}\right) \overline{w(\sigma)}, \\
\chi(\zeta)= & \frac{1}{2 \pi i} \int_{L_{l}} \frac{f_{0} d \sigma}{\sigma-\zeta} \\
\theta^{\prime}(\zeta)= & \frac{1}{2 \pi i} \int_{L_{l}} \frac{f_{0} d \sigma}{\sigma-\zeta}-\zeta \frac{\zeta^{2}+m}{m \zeta^{2}-1} \chi^{\prime}(\zeta), \\
\sigma_{\rho}+\sigma_{\theta}= & 4 \operatorname{Re}\left[\frac{\chi^{\prime}(\zeta)}{w^{\prime}(\zeta)}\right],
\end{aligned}
$$

where in hole edge, $\overline{T_{x}}$ represents surface force component of $x$ direction, $\overline{T_{y}}$ represents surface force component of $y$ direction, $X$ and $Y$ represent, respectively, boundary resultant force of $x$ and $y$ directions, $B, B^{\prime}$, and $C^{\prime}$ are real constants, and $\sigma$ represent the points which locate the boundary of the unit circle on the complex plane $\zeta$.

Since the hole edge pressure is self-balanced and the stress at infinity is 0 , there is $X=Y=B=0$ and $B^{\prime}-i C^{\prime}=0$ : 


$$
\begin{aligned}
f_{0} & =-q \int_{L}(\mathrm{~d} x+i \mathrm{~d} y)=-q R\left(\frac{1}{\zeta}+m \zeta\right), \\
\chi(\zeta) & =-q R m \zeta, \\
\theta_{\prime}(\zeta) & =-q R\left(1+m^{2}\right) \frac{\zeta}{1-m \zeta} .
\end{aligned}
$$

According to the actual situation, $\sigma_{\rho}$ is $-q$ :

$$
\sigma_{\theta}=q \frac{1-\left(3 m^{2}+2 m \cos 2 \theta\right)}{1+\left(m^{2}-2 m \cos 2 \theta\right)} .
$$

Under the action of only considering original rock stress, the calculation formula of circumferential stress around high elliptical roadway is as follows:

$$
\begin{aligned}
& \sigma_{\theta^{\prime}}=P_{0} \frac{2 m^{\prime}}{\cos ^{2} \theta^{\prime}+m^{\prime 2} \sin ^{2} \theta^{\prime}}, \\
& m^{\prime}=\frac{b}{a},
\end{aligned}
$$

where $\theta l$ is the angle between the stress and the vertical axis.

On the arch structure formed by the uniform compression zone, the arch's stress distribution and roadway section are symmetrical about $Y$ axis. Therefore, if the resultant force in $Y$ direction under unit length is greater than 0 , the support scheme can ensure the roadway safe:

$$
\mathrm{d} s=\sqrt{(a \sin \alpha)^{2}+(b \cos \alpha)^{2} \mathrm{~d} \alpha,}
$$

where ds represents an arc length differential length unit, $\alpha$ represents the angle, and $L_{0}$ represents the arc length of $P$ acting on the uniform compression arch.

Under the action of the original rock stress, the $Y$-direction resultant force under unit length of the outer plane on the uniform compression zone can be obtained by the following equation:

$$
Y_{p}=\int_{L_{0}} P \sin \alpha \mathrm{d} s .
$$

Equations (20) and (13) are brought into equation (21) to obtain the following equations:

$$
\begin{aligned}
Y_{P} & =\int_{0}^{\pi} P_{s}\left(\frac{a b+t_{1} \sqrt{(a \sin \alpha)^{2}+(b \cos \alpha)^{2}}}{R_{p} \sqrt{(a \sin \alpha)^{2}+(b \cos \alpha)^{2}}}\right)^{(2 \sin \varphi) /(1-\sin \varphi)} \sin \alpha \sqrt{\left(a^{\prime} \sin \alpha\right)^{2}+\left(b^{\prime} \cos \alpha\right)^{2}} \mathrm{~d} \alpha \\
& =-2 P_{s} \int_{0}^{\pi / 2} \sqrt{a \prime^{2}+\left(b \prime^{2}-a \prime^{2}\right) \cos ^{2} \alpha}\left(\frac{a b+t_{1} \sqrt{a^{2}+\left(b^{2}-a^{2}\right) \cos ^{2} \alpha}}{R_{p} \sqrt{a^{2}+\left(b^{2}-a^{2}\right) \cos ^{2} \alpha}}\right)^{2 \sin \varphi /(1-\sin \varphi)} \mathrm{d} \cos \alpha,
\end{aligned}
$$

where $a$ takes $3.252 \mathrm{~m}, b$ is $3.919 \mathrm{~m}, a^{\prime}$ is $4.302 \mathrm{~m}$, and $b^{\prime}$ is $4.969 \mathrm{~m}$. Bringing each parameter into (25), it can be obtained that $Y_{P}$ is $3.548 \times 10^{4} \mathrm{KN}$.

Without considering the increment of tangential stress along the radial direction, the radial force under unit length of the arch formed by the uniform compression zone under the action of original rock stress can be obtained:

$$
Y_{\theta_{1}}=2 \sigma_{\theta}, t_{1} \text {. }
$$

Bringing each parameter into formula (23), it can be obtained that $Y_{\theta^{\prime}}$ is $6.008 \times 10^{4} \mathrm{KN}$.

In this case, one end of the bolts and cables and grouting body are directly acted on the innermost side of the uniform compression belt, so the supporting force provided by them can be directly superimposed. For the steel tube concrete support, it has no direct action on the uniform compression zone, but the grouting body they act on can be regarded as an elastomer. So, it is not difficult to obtain the equivalent 
supporting force acting on the uniform compression zone. The sum of the forces acting on the uniform compression zone by the above components is $q$ :

$$
\begin{aligned}
\sqrt{\frac{b^{2}-a^{2}}{a^{2}}} & =k \\
\sqrt{\frac{\left(b-h_{c}\right)^{2}-\left(a-h_{c}\right)^{2}}{\left(a-h_{c}\right)^{2}}} & =k_{1}, \\
m_{e} & =\frac{a-b}{a+b-2 h_{c}}, \\
P_{e} & =\frac{\sigma_{0}\left(a-h_{c}\right) 1 / k_{1}\left[k_{1} \sqrt{1+k_{1}^{2}}+\ln \left|k_{1}+\sqrt{1+k_{1}^{2}}\right|\right]-2 \sigma_{0}\left(1-3 m_{e}^{2}+2 m_{e} \cos 2 \theta / 1+m_{e}^{2}-2 m_{e} \cos 2 \theta\right) h_{c}}{a 1 / k\left[k \sqrt{1+k^{2}}+\ln \left|k+\sqrt{1+k^{2}}\right|\right]} .
\end{aligned}
$$

Bringing each parameter into formula (23), it can be obtained that $P_{e}$ is $1.70 \mathrm{MPa}$ :

$$
\begin{aligned}
q & =P_{e}+\sigma_{S}+\sigma_{g}+P_{c} \\
Y_{q} & =\int_{0}^{\pi} q \sin \alpha \sqrt{(a \sin \alpha)^{2}+(b \cos \alpha)^{2} \mathrm{~d} \alpha} \\
& =-2 q \int_{0}^{\pi / 2} \sqrt{a^{2}+\left(b^{2}-a^{2}\right) \cos ^{2} \alpha \mathrm{d} \cos \alpha} \\
\sqrt{\frac{b^{2}-a^{2}}{a^{2}}}=k Y_{q} & =2 q a \frac{1}{k} \int_{0}^{k} \sqrt{1+x^{2}} \mathrm{~d} x=q a \frac{1}{k}\left[k \sqrt{1+k^{2}}+\ln \left|k+\sqrt{1+k^{2}}\right|\right] .
\end{aligned}
$$

Bringing formulas (24) and (25) into formula (27), it can be obtained that $Y_{q}$ is $2.084 \times 10^{4} \mathrm{KN}$.

Without considering the increment of tangential stress along the radial direction, the radial force of the arch formed by the uniform compression zone under the action of support force can be obtained:

$$
Y_{\theta}=2 \sigma_{\theta} t_{1} \text {. }
$$

Bringing each parameter into formula (28), it can be obtained that $Y_{\theta}$ is $4.41724 \times 10^{3} \mathrm{KN}$ :

$$
\sum Y=Y_{\theta_{1}}+Y_{q}-Y_{\theta}-Y_{P}=4.102 \times 10^{4} \mathrm{KN}>0
$$

Above all, the ultimate bearing capacity of the design scheme is higher than the required load of the roadway, which meets the requirements of roadway support. It means that the superimposed bearing structure meets design requirements.

\section{Numerical Simulation Analysis}

6.1. Model Establishment. The numerical model of the roadway is shown in Figure 7, based on FLAC3D simulation software. Considering the boundary effect, the length of the outer boundary and the horizontal direction have more than 8 times the radius of the roadway. The size is $60 \mathrm{~m} * 20 \mathrm{~m} * 40 \mathrm{~m}$ with a total of 67282 units and 91550 nodes. The model adopts the strain softening model. At same time, the uniform load 11.74 $\mathrm{MPa}$ is applied at the top of the model. In the process of tunnel excavation, for the bottom boundary, it is prohibited to move in any directions. For the top boundary, it is free. For other boundaries, it is forbidden to move in any directions, except vertical direction. In the supporting process, the bolts and the cables adopt the cable unit. And, concrete-filled steel tube support adopts the beam unit. The material parameters of the roadway surrounding rock are shown in Table 2. 


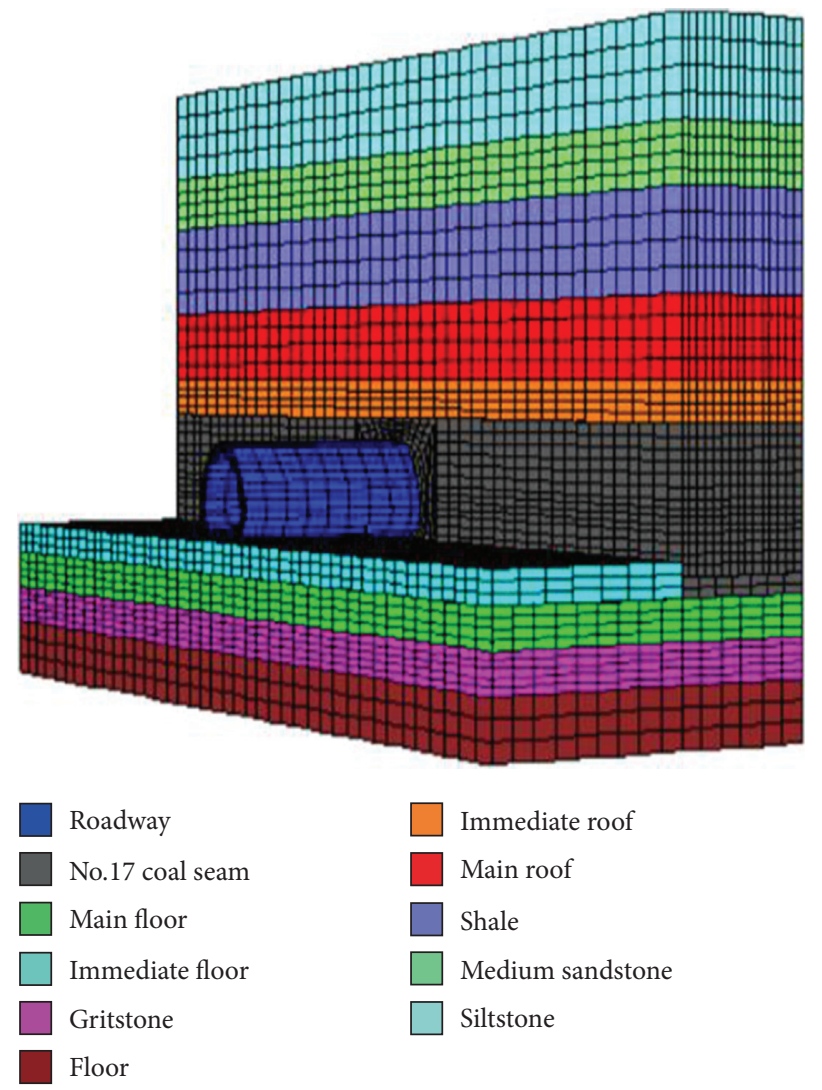

Figure 7: Numerical model of the roadway.

TABLE 2: Rock material parameters.

\begin{tabular}{lcccccc}
\hline Rock & Density $\left(\mathrm{kg} \cdot \mathrm{m}^{-3}\right)$ & Shear modulus $(\mathrm{GPa})$ & Bulk modulus $(\mathrm{GPa})$ & Cohesion $(\mathrm{MPa})$ & $\begin{array}{c}\text { Interfriction } \\
\text { angle }\end{array}$ & $\begin{array}{c}\text { Tensile strength } \\
(\mathrm{MPa})\end{array}$ \\
\hline Mudstone & 2100 & 0.27 & 0.53 & 0.55 & 25 & 0.80 \\
Shale & 2600 & 3.3 & 5.10 & 2.00 & 37 & 2.00 \\
Siltstone & 2200 & 0.47 & 0.91 & 0.81 & 25 & 1.00 \\
Medium sandstone & 2550 & 0.60 & 1.00 & 0.82 & 32 & 1.10 \\
Fine sandstone & 2600 & 0.67 & 0.18 & 0.80 & 30 & 1.15 \\
Coal & 1650 & 0.19 & 1.00 & 0.57 & 24 & 0.65 \\
Gritstone & 2520 & 0.60 & 0.82 & 32 & 1.14 \\
\hline
\end{tabular}

6.2. Result Analysis. Figure 8 shows a comparison of the numerical simulation cloud chart between the roadway without bracing and the roadway with the concrete-filled steel tube support bracing.

6.2.1. Roadway Excavation without Support. After excavation, due to no support measures have been taken, the roadway changed from the three-direction stress state before excavation to the two-direction stress state. This change prompts the roadway instability and deformation. The displacement of roadway surface increases with the excavation time. As shown in Figure 8(a), the maximum subsidence of the roof reaches $300 \mathrm{~mm}$. The maximum size of bottom heave reaches $250 \mathrm{~mm}$. And, the deformation convergence rate reaches $15.32 \%$. Furthermore, the plastic zone of the roadway has great distribution range. The original roadway cannot maintain normal work. Thereby, support should be applied immediately after the excavation of the roadway.

6.2.2. Applying Support. After excavation of the roadway and anchoring the cables and bolts, the concrete-filled steel tube supports are erected in time. There is a gap of $500 \mathrm{~mm}$ between the support and the surrounding rock. After the supports are erected, concrete will be sprayed between the surrounding rock and the supports. At the initial stage of support, the bolts and cables play a main supporting role to maintain the stability of the roadway. As the concrete gradually solidified, the supporting role of the concrete and concrete-filled steel tube supports gradually appears. 




(a)

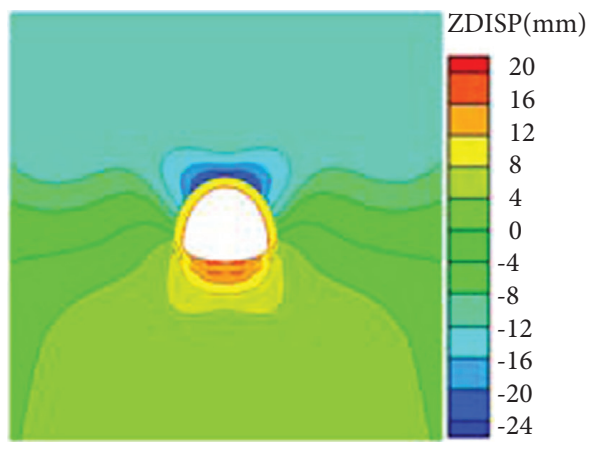

(b)

Figure 8: Roadway surrounding rock displacement contour.
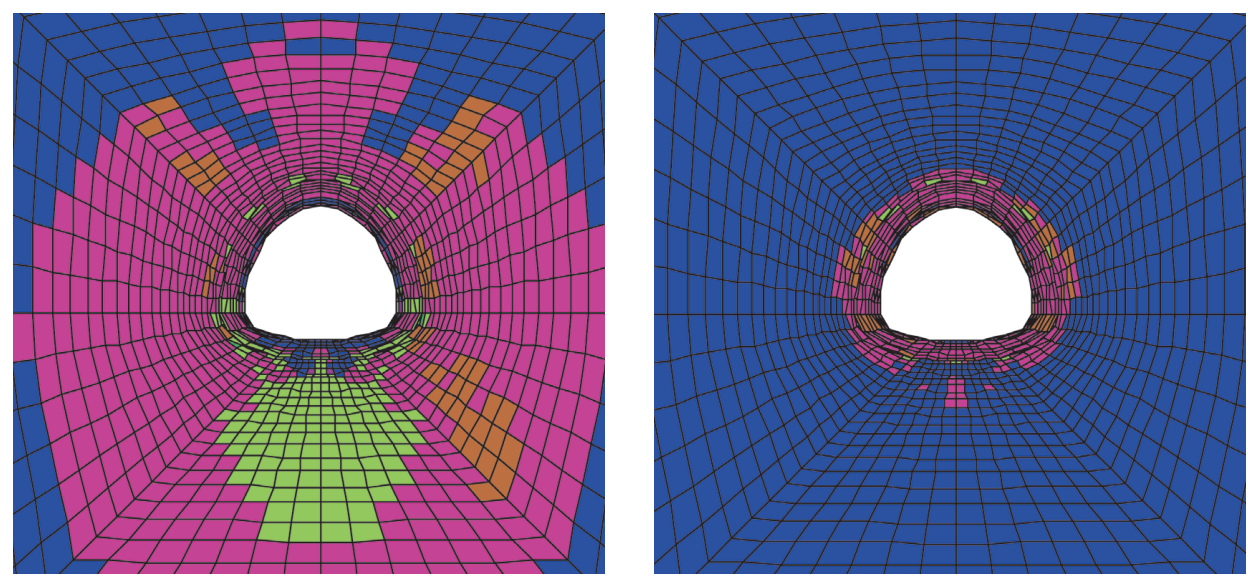



(a)

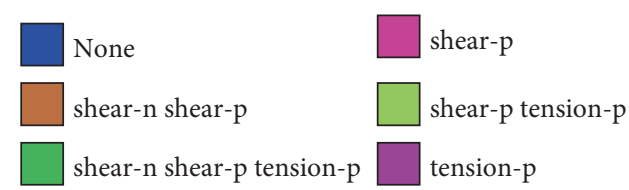

(b)

Figure 9: Plastic zone diagram of roadway surrounding rock.

Meanwhile, the deformation gradually decreases and eventually tends to stabilize. As shown in Figure 8(b), the maximum subsidence of the roof reaches $24 \mathrm{~mm}$. The maximum deformation of the floor reaches $20 \mathrm{~m}$. At the same time, it can be obtained by the plastic zone figure, Figure 9, that the range of the plastic zone significantly reduces. And, the deformation of the surrounding rock is within a controllable extent.

\section{Engineering Application}

7.1. Construction Procedure. The construction procedure of support: (1) widen the roadway section to the designed section; (2) use the cables and bolts for temporary support; (3) install the concrete-filled steel tube supports without filled concrete, lay metal mesh, and noncombustible material cloth, and ensure that there is a gap of $500 \mathrm{~mm}$ between the support and the roadway; (4) spray cement mortar with a spray powder to fill the gap; (5) pour C40 concrete into the concrete-filled steel tube supports.

7.2. Field Measurements. After the completion of supports, the displacement deformation of the floor, roof, and two sides is monitored by the cross-distribution point method. The specific monitoring methods are as follows: monitored every 2 days from the outset to 15th day after detection; monitored every 5 days from 15th day to 40th day after detection; monitored every 10 days from 40th day to 90th day after detection. The monitoring data is shown in Figure 10.

Monitoring results present that the surrounding rock deformation can be divided into three stages:

7.2.1. Rapid Deformation Stage. Within 15th day after the roadway repair is completed, the deformation of the 


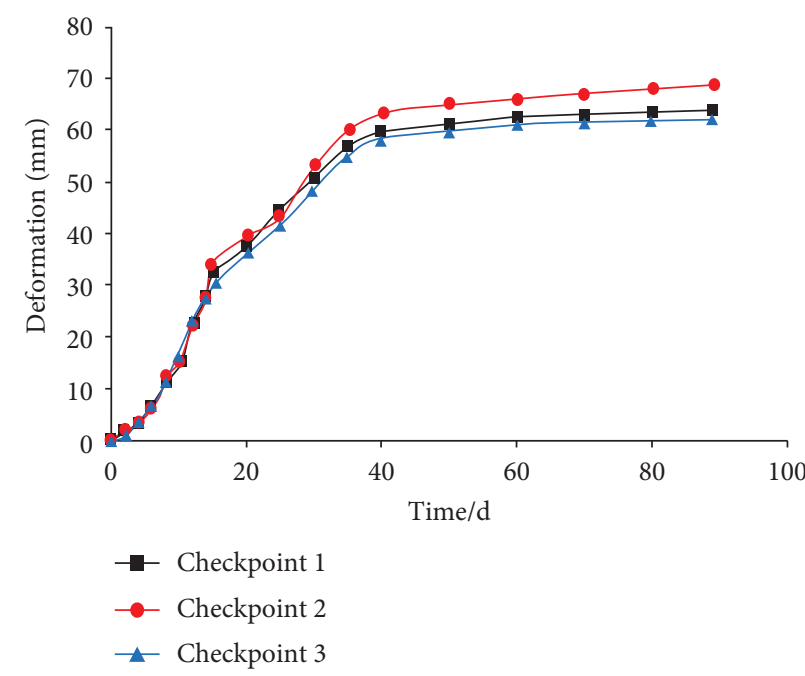

(a)

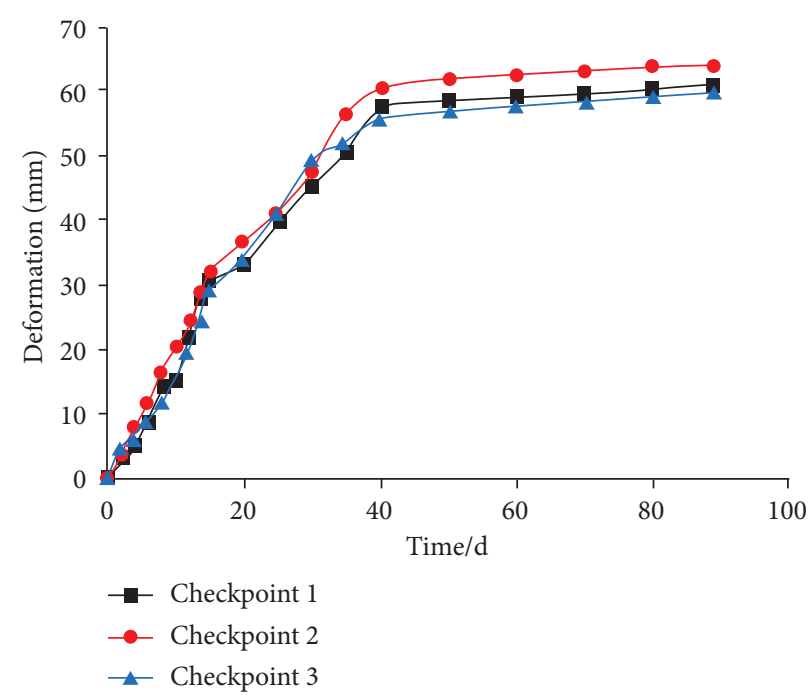

(b)

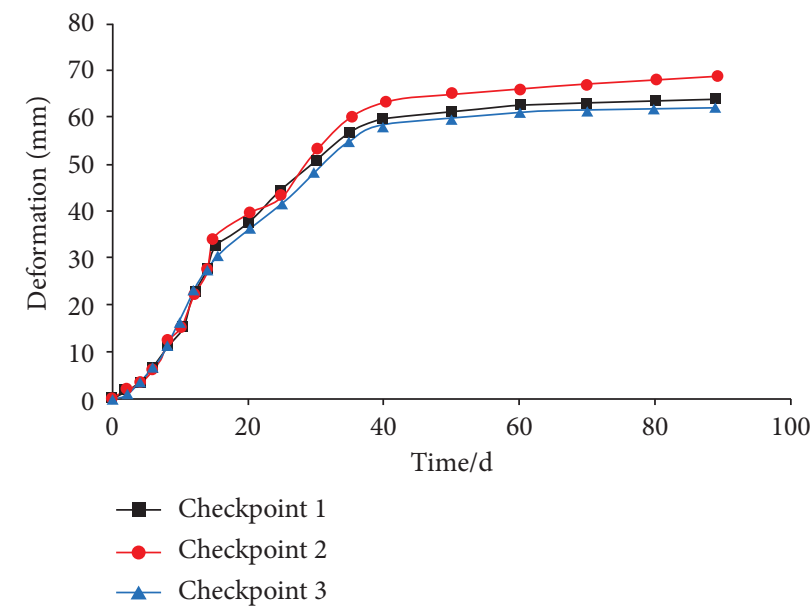

(c)

FIGURE 10: Surrounding rock deformation monitoring graph. (a) Deformation curve of the roof. (b) Deformation curve of the floor. (c) Deformation curve of the two sides.

surrounding rock expresses intense. The maximum deformation among the roof, floor, and two sides reaches, respectively, $34.23 \mathrm{~mm}, 32.12 \mathrm{~mm}$, and $37.58 \mathrm{~mm}$. At this stage, the concrete has not hardened. Therefore, the concrete-filled steel tube supports cannot undertake a supporting role. In other words, the bolts and cables jointly prevent the surrounding rock deformation.

7.2.2. Slow Deformation Stage. Within 15 th day to 45 th day after roadway support, the maximum deformation among the roof, floor, and two sides, respectively, reaches $63.55 \mathrm{~mm}$, $60.46 \mathrm{~mm}$, and $68.45 \mathrm{~mm}$. During the period, the concrete gradually hardens. Hence, the supporting action of concretefilled steel tube support begins to appear. The deformation velocity of the surrounding rock decreased.

7.2.3. Tend to a Stabilized Stage. After 45th day from the roadway support, the deformation speed decreased

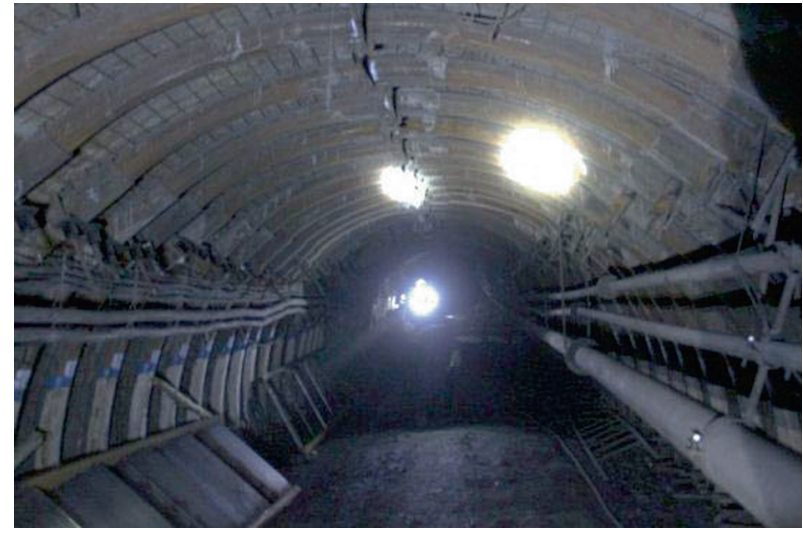

FIgURE 11: 1412 Roadway after support.

obviously. And, the deformation gradually stabilizes. The final deformation among the roof, floor, and two sides reaches, respectively, $69.22 \mathrm{~mm}, 64.11 \mathrm{~mm}$, and $72.45 \mathrm{~mm}$. 
At this stage, the concrete is completely hardened. Thus, the coordination with the concrete and concrete-filled steel tube support provides main bearing capacity, which limits the deformation of the surrounding rock. Meanwhile, the bolts and cables also exert their arch action and suspension action. Figure 11 is the scene figure after the roadway support is completed.

\section{Conclusions}

(1) By means of field investigation and laboratory tests, 1412 Roadway is verified as a typical high-stress soft rock roadway. The instability and deformation basically are caused by low strength, poor self-stability, high stress and complicated stress environment of surrounding rock, lower support resistance of the supporting members and failure to strengthen support for fatal parts.

(2) Combined with the deformation characteristics and the deformation mechanism of the roadway, this paper analyzes and puts forward the composite supporting scheme "cables and bolts + grouting + concrete-filled steel tube support." According to the theoretical calculations and numerical simulations, it has been certified that the ultimate load of the designed composite support scheme is greater than that of the surrounding rock. It means that the scheme can provide sufficient force to maintain the stability of the roadway.

(3) The underground detection shows that the surrounding rock deformation tends to stabilize after supporting 45th day. The maximum deformation among the roof, floor, and two sides of roadway is less than $100 \mathrm{~mm}$, which is within a controllable range. On the whole, it has successfully solved that the difficulty of 1412 Roadway with large deformation and hard support.

\section{Data Availability}

The data used to support the findings of this study are available from the corresponding author upon request.

\section{Conflicts of Interest}

The authors declare that there are no conflicts of interest regarding the publication of this paper.

\section{Acknowledgments}

This work was financially supported by National Natural Science Foundation of China (nos. 51904081 and 51964008), Guizhou Provincial Science and Technology Foundation (Qian Ke He Zhi Cheng [2020]4Y042), and Guizhou Provincial Science and Technology Foundation (Qian Ke He Ji Chu-ZK[2021] Yiban 264).

\section{References}

[1] M. He, H. Xie, S. Peng, and Y. -D. Jiang, "Study on rock mechanics in deep mining engineering," Chinese Journal of Rock Mechanics and Engineering, vol. 24, no. 16, pp. 28032813, 2005.

[2] R. Yang, Y. Li, D. Guo et al., "Deformation reasons and support technology of deep and high-stress soft rock roadway," Journal of Mining \& Safety Engineering, vol. 34, no. 6, pp. 1035-1041, 2017.

[3] M. He, Jinghaihe, and X. Sun, Soft Rock Engineering Mechanics, pp. 47-62, Science Press, Beijing, China, 2002.

[4] H. Zhang, H. Li, Z. Li et al., "Research on surrounding rock deformation mechanism and support technology of deep soft rock roadway," Mining and safety engineering, vol. 32, no. 6, pp. 955-962, 2015.

[5] Q. Meng, L. Han, J. Zhang, S. Wen, F. Zhang, and H. Li, "Research and application of deep high-stress broken soft rock roadway support technology," Journal of Central South University: Natural Science Edition, vol. 47, no. 11, pp. 3861-3872, 2016.

[6] Q. Meng, L. Han, W. Qiao et al., "Numerical simulation of bolt-grouting support mechanism in deep soft rock roadway," The Journal of Mining and Safety Engineering, vol. 33, no. 1, pp. 27-34, 2016.

[7] Y. Gao, X. Li, J. Wang et al., "Numerical simulation analysis of grouting hole reinforcement technology for concrete filled steel tubular support," Tunnel construction, vol. 31, no. 4, pp. 426-430, 2011.

[8] Y. Gao, B. Wang, J. Wang et al., "Concrete filled steel tubular support for deep soft rock roadway Performance test and application of supporting structures," Journal of rock mechanics and engineering, vol. 29, no. S1, pp. 22-27, 2010.

[9] X. Li, R. Yang, Y. Gao et al., "High strength concrete filled steel tubular support technology for large section soft rock inclined shaft," Journal of Coal, vol. 38, no. 10, pp. 17421748, 2013.

[10] K. Liu, Y. Gao, and F. Zhang, "Composite support technology of concrete-filled steel tube support in large section extremely soft rock roadway," Journal of Mining and Safety Engineering, vol. 34, no. 2, pp. 243-250, 2017.

[11] J. Wang, F. Chen, G. Liu et al., "Application of Concrete-filled Steel tube support in the repairing of $1000 \mathrm{~m}$-deep roadway," Tunne Construction, vol. 33, no. 9, pp. 774-778, 2013.

[12] Y. Gao, K. Liu, X He et al., "Steel tube concrete support applied to dynamic pressure roadway in kilometers deep mine," Coal Science and Technology, vol. 43, no. 8, pp. 7-12, 2015.

[13] S. Wang, Z. Lei, and G. Liu, "Design and application of concrete-filled steel tube support," Journal of North China University of Science and Technology, vol. 9, no. 1, pp. 50-54, 2012.

[14] X. Zhang and W. Yan, "Application of concrete-filled steel tube support in deep well support of Huafeng Coal Mine," Coal mine machinery, vol. 32, no. 7, pp. 194-196, 2011.

[15] K. Peng, Z. Dong, X. Li, and Q. Zhu, "Study on soft rock roadway support technology in coal seam scouring zone," Comprehensive utilization of resources in China, vol. 29, no. 7, pp. 47-49, 2011.

[16] M. He, H. Yuan, H. Jing et al., The Theory and Practice of Bolt Support in Chinese Coal Mines, pp. 114-115, Science Press, Beijing, China, 2004.

[17] W. Gao, Rock Mechanics, pp. 149-160, Peking University Press, Beijing, China, 2010. 
[18] W. Yu, Q. Gao, and C. Zhu, "Study of strengthen theory and application of overlap arch bearing body for deep soft surrounding rock," Chinese Journal of Rock Mechanics and Engineering, vol. 29, no. 10, pp. 2134-2142, 2010.

[19] W. Yueguang, "Calculation of elastic-plastic problems of elliptical roadways by perturbation method," Engineering $\mathrm{Me}$ chanics, no. 2, pp. 93-102, 1990.

[20] M. Cai, M. He, and D. Liu, Rock Mechanics and Engineering, Science Press, Beijing, China, 2002.

[21] M. Oda, "Permeability tensor for discontinuous rock masses," Géotechnique, vol. 35, no. 4, pp. 483-495, 1985.

[22] Z. Xu, Brief Course on Elastic Mechanics, Higher Education Press, Bejing, China, 5th edition, 2018. 